\title{
TRAJETÓRIAS ENTRE FRONTEIRAS: O FIM DA ESCRAVIDÃO E O FAZER-SE DA CLASSE TRABALHADORA NO RIO DE JANEIRO*
}

\author{
Marcelo Badaró Mattos**
}

\begin{abstract}
Resumo: Este artigo parte da reflexão sobre a trajetória de alguns militantes das organizações ligadas à classe trabalhadora em formação na cidade do Rio de Janeiro entre as duas últimas décadas do século XIX e as duas primeiras do século XX, para discutir como, a partir do compartilhamento de experiências de trabalho e vida em uma cidade com forte presença da escravidão, ao longo do século XIX, trabalhadores escravizados e "livres" partilharam também formas de organização e de luta, gerando valores e expectativas comuns, que acabariam tendo uma importância central para momentos posteriores do processo de formação da classe.
\end{abstract}

Palavras-chaves: formação da classe trabalhadora; militância; abolicionismo.

Abstract: This article takes into account the trajectory of some militants of working class organizations in the city of Rio de Janeiro, between 1880 and 1920, in order to discuss how enslaved and "free" workers shared experiences of work, city life, organization and ways of struggle, generating common values and expectations that finished to be very important in the working class formation process.

Keywords: working class formation; militancy; abolitionism.

Parto, neste artigo, da reflexão sobre a trajetória de alguns militantes das organizações ligadas à classe trabalhadora em formação na cidade do Rio de Janeiro entre as duas últimas décadas do século XIX e as duas primeiras do século XX. Os argumentos aqui apresentados derivam de um estudo mais amplo, sobre o processo de formação da classe no Rio de Janeiro. ${ }^{1}$ Naquele estudo, procurei abordar, entre outras questões, como, a partir do compartilhamento de experiências de trabalho e vida em uma cidade com forte presença da escravidão, ao longo do século XIX, trabalhadores escravizados e "livres" partilharam também formas de organização e de luta, gerando valores e expectativas comuns, que acabariam tendo uma importância central para momentos posteriores do processo de formação da classe.

\footnotetext{
* Este artigo é fruto da participação na mesa "Trajetórias entre fronteiras: o fim da escravidão e o fazer-se da classe operária no Brasil", realizada durante a IV Jornada Nacional de História do Trabalho, do GT Mundos do Trabalho da ANPUH, em Criciúma, Santa Catarina, em julho de 2008. Agradeço aos comentários de Beatriz Loner, Regina Célia Xavier e aos demais participantes do debate. Ao CNPQ e Faperj o registro do apoio às pesquisas.

** Professor da Universidade Federal Fluminense.

${ }^{1}$ MATTOS, Marcelo Badaró. Escravizados e livres: experiências comuns na formação da classe trabalhadora carioca. Rio de Janeiro: Bom Texto, 2008.
} 
Neste artigo procurei retomar tal questão, enfatizando o cruzamento das trajetórias de diversos militantes cariocas, que construíram organizações sindicais e/ou partidárias de trabalhadores a partir dos anos 1890. Parto, porém, de sua atuação no período anterior, nos anos 1870 e 1880, enfatizando o papel de pólo aglutinador de experiências desempenhado pelo movimento abolicionista.

\title{
UMA TRAJETÓRIA INVULGAR
}

Começo resumindo uma história. Uma história de trabalhadores em padarias, entre 1876 e 1912, contada por um líder da categoria, João de Mattos, num manuscrito localizado entre os papéis apreendidos pela polícia política carioca nos anos 1930 . No manuscrito, João de Mattos registra suas memórias sobre as lutas dos empregados em padarias, desde a época da escravidão até o momento das mobilizações sindicais.

Ela começa em Santos, em 1876, quando trabalhava em padarias da cidade e organizou um "levante", que ele explica ser como "as mesmas greves de hoje". O levante organizado por João de Mattos foi uma paralisação das padarias da cidade, em meio à qual se deu a fuga dos trabalhadores escravizados daqueles estabelecimentos. A fuga foi preparada, com a falsificação de cartas de alforria. João de Mattos foi preso algum tempo depois, mas por falta de provas logo foi posto em liberdade. Ele assim narrou aqueles acontecimentos:

\begin{abstract}
Em Santos existiam 5 padarias. E nós com os convenientes preparos, e com toda a cautela conseguimos o $1^{0}$. Levante geral, devido aos patrões serem muito maus e malvados - com castigos - e mais castigos sem a mínima razão. Às horas combinadas [as padarias] foram todas abandonadas. Eu já tinha todas cartas precisas, porém falsificadas, para cada, de liberdade. Seguimos. E, além deles já estarem bem compenetrados, mais fomos no caminho insinuando-os. E tão bem dispersos foram que não apareceram mais. Passados dois meses fui preso em São Bernardo e me conduziram para a cidade de Santos. Estive preso uns três meses e como não apareceu um só que fosse para provar fui posto em liberdade, condicional de não voltar mais àquela cidade. ${ }^{2}$
\end{abstract}

\footnotetext{
${ }^{2} \mathrm{O}$ manuscrito de João de Mattos está reproduzido em fac-simile, precedido de um estudo introdutório que o contextualiza em DUARTE, Leila. Pão e liberdade: uma história de escravos e livres na virada do século XIX. Rio de Janeiro: Aperj/Faperj/Mauad, 2002, p. 64-65.
} 
Solto, rumou para a cidade de São Paulo, onde organizou outro "levante" bem sucedido, desta vez reunindo 11 ou 12 padarias da cidade, em 1877. Tal qual o de Santos com paralisação, fuga, cartas de alforria falsificadas - tudo deu certo, e os trabalhadores escravizados das padarias paulistanas fugiram na direção do estado do Rio de Janeiro, acompanhados de João de Mattos, que em 1878 chegou à cidade do Rio de Janeiro, então capital do Império do Brasil, onde atuou com os mesmos objetivos.

Com um número muito maior de padarias, para preparar um levante igual aos de Santos e São Paulo, João de Mattos e seus companheiros precisaram criar uma organização, o Bloco de Combate dos Empregados em Padarias. O Bloco tinha sede, estatuto e um lema Pelo pão e pela liberdade - mas precisava funcionar clandestinamente, escondido sob a fachada de um "curso de dança". Afinal, como relata João de Mattos, não podiam "funcionar claramente, era um crime terrível guerrear a propriedade escrava". ${ }^{3}$

O Bloco de Defesa chegou a reunir mais de 100 associados, organizou-se em quatro comissões, fez alguns levantes parciais e, em 1880, um novo levante geral, como o chamou João de Mattos. Os trabalhadores escravizados fugiram em direção a Barra do Piraí, com suas cartas de alforria forjadas e João de Mattos acabou sendo novamente preso, por conta de uma delação. Desta vez, foi defendido pelo propagandista da abolição e da República, Saldanha Marinho, conseguindo ser absolvido.

Porém, quando a escravidão foi abolida, em 1888, as lutas de João de Mattos e dos seus companheiros não foram dadas por terminadas. Afinal, como ele mesmo nos ensina, “em 1888 nós realizamos a maior vitória da nossa intransigente luta, ficando o caminho livre para os escravizados de fato e nós, os escravizados livres, até o presente entremos a lutar."4 Na nova fase das lutas dos padeiros, João de Mattos e seus companheiros organizaram, em 1890, uma associação com o objetivo de reunir recursos para comprar padarias para os próprios trabalhadores, livrando-se dos patrões. Era a Sociedade Cooperativa dos Empregados em Padarias no Brasil - cujo lema era Trabalhar para nós mesmos -, que reuniu cerca de 400 sócios, mas não deu certo, porque o tesoureiro fugiu com o dinheiro da entidade.

\footnotetext{
3 DUARTE, Leila. Pão e liberdade..., p. 67.

${ }^{4}$ Ibid., p. 70.
} 
Os problemas não os levaram a desistir das lutas e, em 1898, fundaram a Sociedade Cosmopolita Protetora dos Empregados em Padarias - com o lema Trabalho, justiça e liberdade: sem distinção de cor, crença ou nacionalidade - que tinha objetivos de auxílio mútuo. Esta Sociedade reuniu mais de mil associados, publicou o jornal O Panificador, organizou uma biblioteca, um centro de educação e acabou adquirindo finalidades de sindicato. Travou, assim, uma luta pelo descanso aos domingos e pela jornada de 8 horas de trabalho, recorrendo a abaixo-assinados às autoridades, que nada resolveram, pois, ainda segundo João de Mattos: "recorrendo a sociedade dirigente nada obtive, porque a política deles é uma e a dos dirigidos é outra." ${ }^{5}$

Depois desses embates, no início do século XX, João de Mattos foi posto pelos donos de padaria em uma "lista negra", não conseguindo mais se empregar neste setor. Os patrões também tentaram dividir o movimento, criando a Liga Federal dos Empregados em Padarias. No entanto, a lição de luta de João de Mattos deixou fortes marcas e, nos anos seguintes, a Liga foi conquistada por militantes combativos, que unificaram a organização da categoria, filiaram mais de 4 mil trabalhadores e realizaram, em 1912 a primeira greve geral dos trabalhadores em padarias na cidade do Rio de Janeiro.

Por que o relato de João de Mattos e da trajetória de luta dos padeiros é importante para entendermos a formação da classe trabalhadora no Brasil? Seguindo as definições clássicas e as iluminações de historiadores sociais contemporâneos ${ }^{6}$, nós lembramos que o processo de formação de classe só pode ser compreendido a partir das condições objetivas que opõem, nas relações sociais de produção, os produtores diretos, àqueles que, detendo os meios de produção, exploram os que nada possuem. No capitalismo, tal oposição objetiva entre os interesses dos proprietários e os dos despossuídos ganha novos contornos, pois os que vendem sua força de trabalho em troca de um salário, adquirem, na experiência comum da exploração a que estão submetidos, a consciência da identidade entre seus interesses, que se opõem aos interesses de seus exploradores, e no bojo deste conflito (a luta de classes), constroem sua consciência de

\footnotetext{
${ }^{5}$ DUARTE, Leila. Pão e liberdade... p. 77.

${ }^{6}$ MARX, Karl e ENGELS, Friedrich. A ideologia alemã. São Paulo: Boitempo, 2007. MARX, Karl. "O 18 de brumário de Louis Bonaparte." In: MARX, Karl e ENGELS, Friedrich. Obras Escolhidas, vol. 1. Moscou/ Lisboa: Progresso/Avante, 1982. THOMPSON, E. P. "Folclore, antropologia e história social”. In: As peculiaridades dos ingleses e outros artigos. Campinas: Editora Unicamp, 2003. THOMPSON, E. P. A Formação da Classe Operária Inglesa. Rio de Janeiro: Paz e Terra, 1987-1988 (3 vols.).
} 
classe. Os valores, discursos e referências culturais que articulam tal consciência, entretanto, não surgem do nada. Desenvolvem-se a partir da experiência da exploração e das lutas de classe anteriores. Ou seja, numa sociedade como a brasileira, marcada por quase quatro séculos de escravidão, não seria possível pensar o surgimento de uma classe trabalhadora assalariada consciente de si sem levar em conta as lutas de classe - e os valores e referências - que se desenrolaram entre os trabalhadores escravizados e seus senhores, particularmente no período final da vigência da escravidão, quando a luta pela liberdade envolve contingentes cada vez mais significativos de pessoas.

\section{OUTRAS TRAJETÓRIAS CRUZADAS}

Podemos pensar nisso através dos cruzamentos de trajetórias de lideranças do movimento dos trabalhadores, a partir da própria narrativa de João de Mattos. Primeiro, é claro, refletindo sobre a sua própria trajetória: liderando "levantes"/greves, cujo objetivo era libertar trabalhadores em padarias escravizados, acumulou uma experiência de lutas e de organização coletiva, que julgou inconclusas quando a escravidão acabou (ainda que julgando uma grande conquista aquele fato). Partiu, então, para construir organizações coletivas que defendessem interesses da classe, com diferentes orientações ao longo das duas décadas seguintes.

Se pensarmos na origem desse manuscrito, muito se pode inferir daquela trajetória. Em janeiro de 1913, após 3 anos de inatividade, volta a ser publicado o jornal $A$ Voz do Trabalhador. Nesse primeiro número da retomada é publicada a circular que havia sido transmitida a entidades de todo país, chamando para a reorganização da Confederação Operária Brasileira (COB) e para a realização de um Segundo Congresso Operário Brasileiro (o Primeiro sendo entendido como o de 1906, que fundara a COB). Em 1o. De abril, o jornal publicou uma quarta circular, buscando ultimar os preparativos para o evento. Entre as orientações ali expressas, destacamos uma:

Lembramos ainda, e frisamos a importância da questão, a grande utilidade dum relatório a respeito da vossa agremiação. Esse relatório deverá formar um histórico 
conciso de todo o movimento passado e presente dessa agremiação, assim como a influência dela no meio operário e social dessa localidade, etc. ${ }^{7}$

Lírio de Rezende e Luiz Antonio Lourenço, receberam a incumbência, pela Liga Federal dos Empregados em Padarias de escrever o relatório da agremiação, atendendo àquela convocação. Tal registro foi publicado pela própria Voz do Trabalhador no ano seguinte (edição de 05/08/1914) e nele constam duas referências a João de Mattos, como primeiro nome da lista dos fundadores da Sociedade Cosmopolita e como organizador da primeira grande assembléia da categoria. Pelas informações ali contidas, percebe-se que os autores do relatório, valorizando a "ação direta", atribuíam a ruína da Cosmopolita, na virada do século, menos à ação patronal do que à interferência de "políticos" - ou seja, de lideranças socialistas que defendiam a via político-partidária-eleitoral como caminho para conquistas dos trabalhadores -, como Evaristo de Moraes.

Apesar de algumas nuances, as informações do relato de João de Mattos, que termina justamente em 1912, parecem ser compatíveis com os comentários do relatório produzido em 1913, o que nos leva a especular que, sendo a liderança mais antiga da categoria, João de Mattos tenha sido instigado a produzir seu "histórico social" como subsídio ao relatório encaminhado à Comissão Organizadora do 20. Congresso Operário. Talvez por isso, dada a ênfase por ele atribuída à continuidade entre a luta pela abolição e as lutas "operárias", possamos compreender como o relatório de 1913 começa afirmando que: “A campanha abolicionista em prol da libertação da escravatura preta, teve seu desfecho em 1888, colocando assim os alforriados em condições de, junto com os trabalhadores brancos, lutarem pela mesma causa." 8

Reunidas essas informações sobre os empregados em padarias, temos já suficientes elementos para avançar em outras direções, mas seguindo as pistas deixadas pelos relatos de João de Mattos e de seus companheiros responsáveis pelo relatório de 1913. Uma primeira pista: João de Mattos, quando de sua prisão no Rio de Janeiro, após o "levante" de 1880, foi defendido por Saldanha Marinho.

Saldanha Marinho não era um operário, nem um militante socialista. Fora presidente de província por duas vezes, deputado por vários mandatos e participou da fundação do Partido Republicano. Podemos especular que defendera João de Mattos por

\footnotetext{
${ }^{7}$ A Voz do Trabalhador, Rio de Janeiro, 01/04/1913.

${ }^{8}$ A Voz do Trabalhador, Rio de Janeiro, 05/08/1914.
} 
sua militância abolicionista, professada de público e acumulada também por sua atividade junto à maçonaria, que vinha de posicionamentos majoritários pelo fim da escravidão desde os anos 1860, segundo relato interno do próprio Saldanha Marinho, escrito em 1884 e citado por Evaristo de Moraes em seu clássico sobre a campanha abolicionista:

Quando apareceu a grande idéia que se converteu na lei de 28 de setembro de 1871, a libertação dos escravos já desde muito preocupava a Maçonaria. A mais de mil escravos deu ela liberdade, e tudo à custa dos metais maçônicos, e sem que se afastasse dos meios legais. Agora que a emancipação se tornou uma aspiração geral, e que necessariamente há de, em breve tempo, ser efetiva, a Maçonaria trata de promover os meios a seu alcance em prol do movimento(...). ${ }^{9}$

Porém, Saldanha Marinho já tinha contatos mais estreitos também com os esforços organizativos dos trabalhadores "livres", numa fase em que os discursos e referências identitárias desses trabalhadores ainda oscilavam muito entre a auto-identificação como "artistas" (artesãos especializados, portadores de um ofício "respeitável") e "operários". Em 1870 foi fundada no Rio de Janeiro a Liga Operária, associação mutual com perfil multiprofissional, que chegou a reunir 1500 associados em torno de objetivos resumidos por Otaviano Hudson, um de seus fundadores: "A igualdade e a fraternidade reinará nesta associação, composta de nacionais e estrangeiros, a divisa será um por todos e todos por um. Proteção mútua, união, amor ao trabalho e instrução". ${ }^{10}$ A Liga não aceitava sócios que não fossem trabalhadores (artistas ou operários), por isso apenas agradeceu a oferta de "prestação de serviços" de diversas personalidades, entre elas Saldanha Marinho.

Já em 1880, em outra iniciativa semelhante, foi criado o Corpo Coletivo União Operária. Organizado em moldes bastante parecidos com os da Liga e com a participação de alguns militantes em comum, como o próprio Otaviano Hudson, o Corpo Coletivo, embora apresentando objetivos de classe relativamente nítidos em seus estatutos - "tratar dos interesses gerais da classe operária e das artes no país" - apresentava maior abertura para a colaboração de elementos externos à classe, prevendo, além dos membros efetivos (que deviam ser "operário, artista ou ter um trabalho material definido"), a possibilidade de associação de membros auxiliares, consultores, honorários e correspondentes. Isso explica

\footnotetext{
9 MORAES, Evaristo. A campanha abolicionista. 2aed., Brasília: EdUnb, 1986, p. 241.

10 Tribuna Artística, Rio de Janeiro, 25/02/1872. Sobre a Liga ver BATALHA, Cláudio. Sociedades de trabalhadores no Rio de Janeiro do século XIX: algumas reflexões em torno da formação da classe operária. Cadernos do AEL, n. 11/12, Campinas: 2000. VITORINO, Artur J. R. Máquinas e operários: mudança técnica e sindicalismo gráfico (São Paulo e Rio de Janeiro, 1858-1912). São Paulo: Annablume/Fapesp, 2000.
} 
que, montados seus Corpos Consultores, em oito áreas, neles estivessem figurando nomes como os de André Rebouças, Benjamin Constant, Vicente de Souza e Saldanha Marinho abolicionistas, positivistas, republicanos, engajados ou ao menos solidários com a proposta da União Operária. Um fator a relativizar hipóteses de autonomia de classe absoluta na organização daquela entidade, porém um bom indicador da capacidade de articulação política entre os trabalhadores e outros setores sociais.

Tanto a Liga Operária quanto o Corpo Coletivo se destacavam pelo seu caráter "inter-categorial", mas eram parte de um impulso associativo bem mais amplo. Investigando estatutos e processos de registro, podemos localizar centenas dessas organizações com finalidades de auxílio mútuo. Eduardo Stotz localizou 67 associações de caráter cosmopolita e 48 de cunho profissional em $1883^{11}$. Cláudio Batalha encontrou, em seu levantamento, o registro da criação de 47 associações entre os anos de 1835 e 1899 ${ }^{12}$. De nossa parte, a partir de estatutos e relatórios depositados na Biblioteca Nacional e de processos ao Conselho de Estado armazenados no Arquivo Nacional, encontramos mais de 180 associações mutuais, beneficentes ou assemelhadas, entre as décadas de 1850 e 1900.

É preciso destacar, porém, que o movimento abolicionista era, naquela quadra, o principal catalisador de associações e articulações, como podemos observar pelo cruzamento com outra figura militante que aparece nesta mesma referência. O professor do Colégio Pedro II Vicente de Souza, que nas décadas de 1890 e 1900 viria a participar das iniciativas de organização de partidos operários/socialistas. Nos primeiros anos do século XX, foi o presidente do Centro das Classes Operárias (CCO), que em 1904 teria papel de destaque na campanha contra a vacinação obrigatória, um dos estopins da "revolta da vacina". Por sua atuação no CCO e em função da revolta, Vicente de Souza seria preso e processado.

Mas, voltando no tempo, quando ainda era um propagandista da abolição e da república, sem maiores explicitações de simpatia socialista, Vicente de Souza, como se vê por sua participação entre os consultores do Corpo Coletivo de 1880, já mantinha vínculos estreitos com organizações de trabalhadores. E o abolicionismo parecia ser a origem desses laços. Afinal, um ano antes, em 23 de março de 1879, proferiu no Teatro São Luiz, a

\footnotetext{
11 STOTZ, Eduardo. A formação da classe operária: Rio de Janeiro, 1870-1890. Niterói, 1984, mimeo. (relatório de pesquisa), p. 66.

12 BATALHA, Cláudio. "Sociedades de trabalhadores no Rio de Janeiro...", op. cit.
} 
conferência "O Império e a Escravidão: o parlamento e a pena de morte". Seu objeto específico era a denúncia do caráter retrógrado da proposta do Deputado Martin Francisco, que, sob o pretexto de evitar crimes de escravos, que atribuía a uma opção consciente destes pela pena de galés (trabalho forçado), propunha a adoção da pena de morte para assassinatos conduzidos por escravos. Embora definindo os africanos como "brutais como a selvageria do hipopótamo, selvagens como a brutalidade de suas guerras", Vicente de Souza atribuía os crimes praticados por escravos ao fato de não lhes ser aberto o caminho do recurso à Lei, sob um argumento de defesa do direito de propriedade dos senhores, que se pautava numa conquista, num roubo da própria humanidade dos cativos ${ }^{13}$.

Embora voltada para a questão da escravidão, a fala de Vicente de Souza naquela ocasião continha diversas referências à situação de classe dos operários, resultante, em sua análise, das políticas econômicas ortodoxas dos gabinetes imperiais:

Economizam tudo, e para salvarem as finanças do país comprometidas espantosamente pelos conservadores, no seu desvario de esbanjamento, lançam mão do operário e expelem-no da oficina (...) Apontar o meio da rua ao operário, em vez de dar-lhe meios de labor, pode ser tudo cidadãos, menos alguma coisa justificável. ${ }^{14}$

A conferência ocorreu cerca de duas semanas depois do discurso de Jerônimo Sodré no parlamento defendendo a abolição imediata, consagrado por Joaquim Nabuco como marco inicial do movimento abolicionista. Marco por sinal contestado por João de Mattos, que afirmou serem os empregados em padaria "os pioneiros abolicionistas" (pois suas lutas começam anos antes). Cabe, porém destacar que a conferência de Vicente de Souza foi organizada e convocada pela Imperial Associação Tipográfica Fluminense, uma das primeiras e mais importantes mutuais do período, que já na década de 1850 havia sustentado com seus fundos a greve dos compositores tipográficos dos jornais diários da Corte, por muitos considerada a primeira greve no Brasil ${ }^{15}$.

A participação dos tipógrafos no movimento abolicionista não se resumiria à propaganda, pois em 1883, quando da fundação da Confederação Abolicionista, no Rio de Janeiro, uma das entidades confederadas era o Clube Abolicionista Gutemberg, criado pelos

\footnotetext{
${ }^{13}$ Conferência realizada no Teatro São Luís em benefício da Associação Tipográfica Fluminense, em 23 de março de 1879, por Vicente de Souza. Tese: o Império e a escravidão, o parlamento e a pena de morte. Rio de Janeiro, Tipografia De Molarinho e Montalverde, 1879, p. 15, 28 ss. (AMORJ, microfilmes, P1).

14 Idem, p. 22.

15 VITORINO, A. Máquinas e operários..., op. cit.
} 
tipógrafos cariocas. Vários seriam também os registros de tipógrafos atuando nas faces extra-legais do movimento abolicionista e mesmo de tipografias que serviam como esconderijo para trabalhadores escravizados em fuga, nos anos finais da escravidão. Em 1884, por exemplo, o relatório de atividades da Confederação Abolicionista, trazia informações detalhadas sobre uma ação direta de libertação de escravos através de comissões numerosas que percorriam determinadas regiões da cidade "convencendo" os senhores a libertarem seus escravos. O sucesso da ação era demonstrado pelo resultado do trabalho da comissão nas ruas Uruguaiana, do Ouvidor, do Teatro e no Largo de São Francisco, ou seja, nos principais quarteirões comerciais e pontos importantes de transporte coletivo do Centro na época, o que explicaria a fúria dos proprietários em face de tal avanço da luta pela libertação:

\begin{abstract}
A idéia de libertação dos escravizados do Município Neutro, posta em prática pela Confederação, já teve o seu princípio. O primeiro quarteirão livre foi o da Rua Uruguaiana, em que está estabelecida a Gazeta da Tarde. A Rua Nova do Ouvidor já não tem mais escravos. O processo foi simples para obter este magnífico resultado; foram organizadas comissões formadas por membros da Confederação e alguns moradores de ruas livres. Juntos obtiveram cartas de liberdade para os escravizados, sem indenização. A notícia desta vitória, e de outra igual, obtida pelo mesmo sistema, por parte do Centro Abolicionista da Escola Politécnica que libertou o Largo de São Francisco de Paula e a Rua do Teatro, alarmou os negreiros, que trataram logo de reunir todos os elementos de combate contra nós. ${ }^{16}$
\end{abstract}

Cabe atentar para um detalhe da narrativa que Evaristo de Moraes desenvolve sobre o episódio. Segundo ele, da comissão encarregada dessa tarefa participava Procópio Russel (tipógrafo da Imprensa Nacional) ${ }^{17}$. Em depoimento atribuído por Eduardo Silva a André Rebouças, percebe-se que os tipógrafos e outros setores operários estavam presentes de forma ativa na fase final da luta contra a escravidão, apoiando as fugas em massa e a formação dos "quilombos abolicionistas". Casas e locais de trabalho haviam sido utilizados como refúgio de trabalhadores escravizados que escapavam ao controle senhorial:

Nas casas das famílias abolicionistas, nos escritórios comerciais, nas redações dos jornais, nos hotéis, nas padarias, nas grandes fábricas, nos quartéis, nas tipografias, por

\footnotetext{
${ }^{16}$ Relatório do Estado e das Operações da Confederação Abolicionista. Gazeta da Tarde. Rio de Janeiro, 29/5/1884, p. 2-3.

17 MORAES, Evaristo de. A Campanha..., op. cit., p. 50.
} 
toda a parte em que houvesse alguma alma abolicionista, encontrava-se um abrigo seguro para guardar a pobre gente. ${ }^{18}$

Ou seja, os trabalhadores assalariados, que compartilhavam espaços de trabalho e de vida urbana com os escravizados, atuaram coletiva e organizadamente pela sua libertação, demonstrando que este tipo de solidariedade na luta pela liberdade era parte do arsenal de valores da nova classe em formação.

Tipógrafos abolicionistas, tipógrafos republicanos, tipógrafos socialistas. Esse parece ter sido um caminho possível e nele podemos compreender a trajetória de José Veiga, tipógrafo que em 1871/1872 estava a frente da Tribuna Artística, órgão de imprensa que divulgou as propostas da Liga Operária. O mesmo José Veiga seria, em 1890, o fundador do Jornal $A$ Voz do Povo, ao redor do qual se reuniriam (e depois divergiriam) os primeiros proponentes de um partido operário, como instrumento de representação dos interesses dos trabalhadores na república recém-implantada, na qual se esperava estariam abertos os espaços para conquistas de direitos pela classe, através de reformas introduzidas na legislação. José Veiga faleceu ainda em 1890, mas a proposta do Partido Operário foi sustentada por dois grupos, um deles, defendendo a autonomia da classe contra a liderança de políticos de outras extrações sociais, seria liderado por outro tipógrafo, negro, chamado Luíz França e Silva. França e Silva defendeu, em 1890, um partido operário com perfil de classe, mas com plataforma bastante moderada (condenando as greves, por exemplo), apostando na possibilidade de conquista de espaço parlamentar por legítimos representantes operários e, através destes, da implantação gradual de reformas legais que pudessem garantir a respeitabilidade e a dignidade dos que vivam do próprio trabalho.

França e Silva logo se decepcionaria com as possibilidades abertas pela República aos operários e, em 1892, estava à frente da convocação do Congresso Operário Nacional, realizado no Rio de Janeiro, que resolve pela criação de um Partido Operário do Brasil. Nas resoluções do Congresso encontramos uma série de reivindicações de direitos políticos e sociais, mas também uma primeira explicitação de posições socialistas - como o questionamento à propriedade privada, presente na apresentação do programa adotado que demonstravam um caminho possível de passagem do republicanismo ao socialismo por

\footnotetext{
${ }^{18}$ Apud, SILVA, Eduardo. As camélias do Leblon e a abolição da escravatura: uma investigação de história cultural. São Paulo: Cia. das Letras, 2003, p. 97.
} 
parte dos militantes engajados nas organizações e lutas da classe trabalhadora em formação.

Algo que ficava explícito na fala de Vicente de Souza, no primeiro de maio de 1898:

O socialismo no Brasil, perante a forma republicana, já agora iludida e falseada em todas as relações que serviram de base à propaganda e às promessas, recolhe no seu seio a grande multidão dos que esperam ainda a verdade do republicanismo radical. Não há, não pode haver antagonismo entre as duas denominações pois que o socialismo, em sua inteira e exata acepção é a forma social e política que realiza todas as promessas, todas as aspirações e todas as soluções do problema republicano. ${ }^{19}$

Vicente de Souza faz esse percurso do abolicionismo ao socialismo ao lado de militantes tipógrafos, como José Veiga e França e Silva, da conferência abolicionista de 1879 às discussões no interior da Voz do Povo de 1890, das quais participou, assim como das várias tentativas de fundação de partidos operários nos anos seguintes, com as quais sempre esteve envolvido.

Percurso semelhante ao percorrido por Evaristo de Moraes, que neste texto aparece mencionado pela primeira vez no relatório da Liga Federal dos Empregados em Padarias, encaminhado ao Congresso Operário de 1913. O adolescente negro, que aos 16 anos cobrira os momentos finais da escravidão na Corte para a imprensa local, nos anos seguintes participaria das mesmas discussões sobre a criação de partidos operários, aderindo ao socialismo nos anos 1890, quando parece ter cruzado com as lutas de João de Mattos e dos empregados em padarias. Sintomaticamente, Evaristo, que se transformaria em advogado e defensor das reformas legais a favor dos trabalhadores, teria papel ativo na organização ou apoio a novas entidades que assumiam perfil de atuação sindical em grupos profissionais com forte tradição de participação nas lutas pela liberdade - como no caso dos empregados em padaria, aqui mais detidamente comentado, mas também no dos trabalhadores do porto, de forte presença negra/ex-escrava. ${ }^{20}$

\footnotetext{
${ }^{19}$ Apud BATALHA, Claudio. "A difusão do marxismo e os socialistas brasileiros na virada do século XIX". In: MORAES, João Quartim (org.). História do Marxismo no Brasil. vol. Il. Campinas: EdUnicamp, 1995, p. 29.

${ }^{20}$ Sobre a trajetória de Evaristo ver MENDONÇA, Joseli. Evaristo de Moraes, tribuno da República. Campinas: EdUnicamp, 2003. Sobre os trabalhadores do porto do Rio de Janeiro, ver CRUZ, Maria Cecília Velasco e. Tradições negras na formação de um sindicato: sociedade de resistência dos trabalhadores em trapiche e café, Rio de Janeiro, 1905-1930. Afro-Ásia, n. 24. Salvador, 2000.
} 


\section{DAS LIDERANÇAS À CLASSE}

Padeiros e estivadores são apenas alguns dos grupos de trabalhadores para quem a experiência da escravidão ou do convívio cotidiano com ela deveria estar muito viva na memória quando, na virada do século XIX para o XX, começaram a construir organizações e ações coletivas com linhas de classe mais nítidas.

Como se percebe na análise de um trabalhador de padarias, publicada em 1908 no jornal A Voz do Trabalhador: “A lei de 88 que aboliu a escravidão no Brasil parece que só não atingiu os operários padeiros, mais escravos do que foram os daquela raça, porque de todos os gananciosos e exploradores sobressaem os donos de padaria". Argumento que se mantinha, alguns anos depois, nas palavras de outro trabalhador, este um estivador:

É fato que acabou a escravatura em 13 de maio de 1888, e diz ainda o adajo popular que 'contra os fatos não há argumentos'; porém, eu digo que há. Há porque se bem que a escravatura acabou, não acabou no pensamento dos nossos algozes, que são estes para quem nós derramamos até a última gota de suor e que não nos sabem recompensar, e nunca saberão, se a isso não os obrigarmos por nossas próprias mãos. A essa classe de gente nós denominamos, na nossa linguagem operária - burgueses. ${ }^{21}$

Lutar pela liberdade era pois um valor fundamental, construído no contexto da luta entre escravos e senhores, mas que se incorporava à nova consciência da classe trabalhadora assalariada em formação. Por isso, no relato de João de Mattos que abriu essa discussão, ao referir-se aos trabalhadores escravizados (ele não fala em escravos, pois não nasceram assim, foram escravizados por outros), ele os chama de "escravizados de fato", contrastando-os não com "trabalhadores livres", mas com os "escravizados livres", porque para ele a luta pela liberdade não estava completa, já os trabalhadores assalariados possuíam, em suas palavras, apenas "o direito de escolher entre este ou aquele senhor" ${ }^{22}$

O que se procurou identificar aqui, a partir da discussão sobre algumas trajetórias de lideranças, foi o impacto político do compartilhamento de experiências de trabalho e vida em algumas cidades brasileiras com forte presença da escravidão, ao longo do século XIX. Tais trajetórias e seus cruzamentos foram possíveis porque trabalhadores escravizados e livres partilharam formas de organização e de luta, gerando valores e expectativas comuns,

\footnotetext{
${ }^{21}$ A Voz do Trabalhador, Rio de Janeiro, 01/07/1913, p. 2.

22 DUARTE, L. Pão e liberdade..., op. cit., p.71.
} 
que acabariam tendo uma importância central para momentos posteriores do processo de formação da classe.

O abolicionismo, como momento mais forte da luta pela liberdade, acabou ocupando um papel catalizador. Naquele movimento, em que o protagonismo foi desempenhado pelos próprios escravizados, percebe-se claramente o apoio de outros segmentos sociais à causa, particularmente dos trabalhadores livres em algumas de suas primeiras organizações. Lideranças abolicionistas se aproximaram das organizações operárias em construção e por suas trajetórias posteriores podemos perceber como os valores forjados naquela luta pela liberdade passaram a fazer parte do arsenal compartilhado pelos trabalhadores nas décadas seguintes, servindo mesmo de parâmetro para a avaliação das experiências e lutas subseqüentes.

João de Mattos, França e Silva, Vicente de Souza, Evaristo de Moraes e outros militantes aqui mencionados não podem ser tomados como "trajetórias exemplares", nem tampouco podemos reduzir a classe trabalhadora em formação ao perfil dessas lideranças. Porém, nos movimentos e organizações em que se encontraram, acreditamos poder enxergar um caminho de acúmulo de experiências fundamentais para a formação da classe trabalhadora carioca. 